\title{
Mordida aberta anterior e hábitos orais em crianças
}

\author{
Anterior open bite and oral habits in children
}

\author{
Gabriela Nascimento Lima ${ }^{1}$, Cibele de Melo Cordeiro ${ }^{2}$, Janize da Silva Justo ${ }^{3}$, \\ Lidiane Cristina Barraviera Rodrigues ${ }^{4}$
}

\begin{abstract}
RESUMO
Objetivo: Verificar o número de pré-escolares com mordida aberta anterior e a associação com os hábitos orais. Métodos: O universo do estudo foi formado por 275 pré-escolares, de ambos os gêneros, com idade entre quatro e seis anos, com dentição decídua completa. Este estudo foi desenvolvido em duas etapas: uma triagem para selecionar as crianças que apresentavam mordida aberta anterior e aplicação de questionário sobre aleitamento materno e hábitos orais com pais/responsáveis das 59 crianças, cuja mordida aberta anterior foi detectada. Os dados foram analisados estatisticamente pelo teste de Igualdade de Duas Proporções e o teste Quiquadrado. Resultados: A porcentagem de crianças com mordida aberta anterior foi de 21,45\% (N=59), sem variação significativa quanto ao gênero. Verificou-se que $93,20 \%(\mathrm{~N}=55)$ das crianças foram amamentadas, sendo que $54,5 \%(\mathrm{~N}=30)$ destas o fizeram por um período igual ou maior que seis meses. Constatou-se que a maioria das crianças com mordida aberta anterior apresentou hábitos de sucção como mamadeira, chupeta e dedo, 98,30\% (N=58). Foi encontrada maior ocorrência para as crianças que permaneciam com a boca aberta durante a noite e que também faziam uso de mamadeira $(90,9 \%)$. Dentre os hábitos orais, a associação mais prevalente foi de mamadeira e chupeta, com 49,2\%. Conclusão: Os resultados indicaram presença de mordida aberta anterior, associação do uso de mamadeira e chupeta, relação da mordida aberta anterior e hábitos orais como mamadeira e chupeta, e relação entre crianças que permaneciam com a boca aberta durante a noite e uso de mamadeira.
\end{abstract}

Descritores: Pré-escolar; Mordida aberta; Mamadeiras; Sucção de dedo; Respiração bucal; Aleitamento materno

\section{INTRODUÇÃO}

Durante o curso normal de erupção dentária é de se esperar que os dentes, juntamente com o osso alveolar que os circunda, desenvolvam-se até encontrar seu antagonista oclusal no arco oposto, ocorrendo um relacionamento vertical do arco maxilar e mandibular ${ }^{(1)}$. No entanto, certos fatores como os hábitos de sucção, a função ou tamanho anormal da língua, a respiração oral, o padrão de crescimento vertical e as patologias congênitas ou adquiridas podem dar origem a desequilíbrios

Trabalho realizado na Escola Municipal Monteiro Lobato - Rio Branco (AC), Brasil, como parte da monografia de conclusão do Curso de Especialização em Motricidade Orofacial da Faculdade São Lucas - FSL - Porto Velho (RO), Brasil.

(1) Pós-graduanda (Especialização) em Saúde Mental pela Universidade Federal do Estado do Acre - UFAC - Rio Branco (AC), Brasil.

(2) Fonoaudióloga clínica; Especialização em Motricidade Orofacial pela Faculdade São Lucas - FSL - Porto Velho (RO), Brasil, e em Psicopedagogia pelas Faculdades Integradas de Várzea Grande - AVEC - Várzea Grande (MT), Brasil.

(3) Fonoaudióloga clínica; Especialização em Motricidade Orofacial pela Faculdade São Lucas - FSL - Porto Velho (RO), Brasil.

(4) Mestre, Professora do Curso de Fonoaudiologia da Faculdade São Lucas - FSL - Porto Velho (RO), Brasil.

Endereço para correspondência: Cibele de Melo Cordeiro. Conj. Bela Vista I, Q-20, C-3, Floresta, Porto Velho (RO), Brasil, CEP: 69906-370. E-mail: cybele.melo@hotmail.com

Recebido em: 28/02/2009; Aceito em: 30/12/2009 oclusais, determinando más oclusões dentárias, dentre elas, a mordida aberta ${ }^{(2-4)}$.

A mordida aberta é definida como uma deficiência no contato vertical normal entre os dentes antagonistas, podendo manifestar-se em uma região limitada ou, mais raramente, em todo o arco dentário. Se a falta de contato entre os dentes localiza-se na região de incisivos e/ou caninos quando a oclusão está em relação cêntrica, esta passa a ser denominada de mordida aberta anterior ${ }^{(4)}$.

A etiologia da mordida aberta anterior é multifatorial e está quase sempre associada a uma desarmonia miofuncional orofacial, seja por fatores genéticos ou pela ação prolongada de hábitos orais ${ }^{(1)}$.

Crianças alimentadas utilizando a mamadeira estão mais predispostas à sucção digital do que as que receberam aleitamento materno, pois a mamadeira não satisfaz a necessidade que a criança tem de sugar ${ }^{(1)}$.

Alguns estudos comprovam que a pouca duração do aleitamento natural está associada à presença de hábitos de sucção constantes em crianças com a dentição decídua completa e a presença dos hábitos orais está associada à ocorrência da má oclusão(5,6).

Durante a sucção digital, se o polegar estiver sustentado para cima contra o palato, será observada a protrusão dos dentes ântero-superiores. Além disso, pode forçar a mandíbula a assumir uma posição retraída. Quando os incisivos superiores 
estiverem inclinados vestibularmente, torna-se necessário que a língua seja projetada para frente durante a deglutição para promover selamento anterior ${ }^{(4)}$.

A sucção de chupeta tem sido estimulada pelos pais, devido a seus efeitos calmantes quando na presença do choro infantil. Alguns estudos até estimulam seu uso, levando-se em conta seus efeitos menos deletérios que a sucção digital e o fato de seu abandono ser mais fácil ${ }^{(6)}$.

A respiração oral é um padrão respiratório que pode determinar modificações na posição dos dentes, mandíbula e língua, além da falta de vedamento da cavidade oral pela ausência de contato entre os lábios, causando respostas neuromusculares indevidas para o correto crescimento e desenvolvimento craniofacial. Dependendo da sua duração, também pode ocasionar alterações funcionais, estruturais, patológicas, posturais, oclusais e de comportamento ${ }^{(7)}$.

Deve-se ressaltar que os efeitos dos hábitos orais sobre a dentição dependem de fatores como a frequência, intensidade e duração do hábito ${ }^{(8)}$.

Alguns autores concordam que é possível a auto-correção da má oclusão, desde que o hábito oral seja removido até a idade de três anos a três anos e seis meses e se a criança possuir um padrão de crescimento facial favorável ${ }^{(9,10)}$.

Verificando as inúmeras alterações que os hábitos orais podem provocar no sistema estomatognático, o fonoaudiólogo tem fundamental importância na prevenção, detecção e retirada dos hábitos, diminuindo a ocorrência das alterações.

Dessa forma, este estudo teve a proposta de verificar o número de pré-escolares com mordida aberta anterior e a associação com os hábitos orais.

\section{MÉTODOS}

Esta pesquisa foi iniciada após aprovação do Comitê de Ética em Pesquisa da Faculdade São Lucas (processo ${ }^{\circ}$ 214/08) e autorização da diretora da Escola Municipal Monteiro Lobato para realização do estudo com seus alunos, em suas dependências. Foram seguidas todas as recomendações da resolução 196/96 do Conselho Nacional de Saúde.

A amostra inicial foi composta por 275 crianças, de ambos os gêneros, entre quatro e seis anos, matriculadas na Escola Municipal Monteiro Lobato, da cidade de Rio Branco (AC). A intenção do presente estudo era avaliar, aproximadamente, 306 crianças pré-escolares; no entanto, nem todos os pais devolveram o Termo de Consentimento Livre e Esclarecido, impossibilitando a inclusão do seu filho nesta pesquisa.

Excluiu-se do estudo crianças que utilizavam aparelho ortodôntico, com ausência dos elementos dentários ânterosuperiores por trauma ou condições fisiológicas (troca de dentição) e que apresentavam malformação craniofacial. Os critérios de inclusão foram: apresentar entre quatro e seis anos de idade e estar na fase de dentição decídua completa.

Inicialmente foi realizada uma reunião de esclarecimento da pesquisa aos pais e/ou responsáveis e entrega do Termo de Consentimento Livre e Esclarecido.

Em seguida, realizou-se uma triagem, a fim de selecionar as crianças que apresentavam mordida aberta anterior. Isto foi verificado na sala de aula de cada turma, solicitando que a criança mantivesse os dentes ocluídos enquanto a avaliadora separava os lábios com os dedos indicador e polegar, observando se havia falta de contato entre os dentes anteriores. Foram levadas em consideração todas as normas de biossegurança preconizadas, sendo realizado sob luz natural, com a criança posicionando-se sentada confortavelmente em frente à examinadora.

Para todas as crianças com mordida aberta anterior foi enviado aos pais/responsável, junto ao caderno de tarefas, um questionário elaborado pelas autoras sobre amamentação e hábitos orais. O questionário foi baseado em outros estudos ${ }^{(11,12)}$ e foi composto por questões estruturadas e semi-estruturadas sobre o tipo de aleitamento materno (natural e/ou artificial); hábitos orais (chupeta, mamadeira, sucção digital); tipo de bico da chupeta e mamadeira utilizada, além da frequência e duração dos hábitos; presença ou ausência da permanência de boca aberta durante o dia e à noite, aspectos respiratórios e tratamentos realizados.

Foram incluídas na amostra final as crianças com mordida aberta anterior e que os pais responderam ao questionário. A amostra final foi composta por 59 crianças, o que corresponde a $21,45 \%$ da amostra inicial, sendo $42,4 \%(\mathrm{~N}=25)$ do sexo masculino e $57,6 \%(\mathrm{~N}=34)$ do sexo feminino, com média de idade de 5,07 anos $( \pm 0,17)$.

Para os pais/responsáveis das crianças que apresentavam hábitos orais foi entregue um folheto explicativo desenvolvido pelas pesquisadoras, sobre os prejuízos desses hábitos.

Para a análise dos resultados, foi utilizado o Teste de Igualdade de Duas Proporções ${ }^{(13)}$, a fim de comparar se a proporção de respostas do questionário de duas variáveis e/ou seus níveis eram significativos; e o teste de Qui-quadrado ${ }^{(13)}$ para medir o grau de relação entre as questões que envolviam manter a boca aberta durante a manhã e noite com o uso da mamadeira, chupeta e sucção digital. Foi definido o nível de significância estatística de 5\% $(\mathrm{p}<0,05)$.

\section{RESULTADOS}

A grande maioria dos pais, ou seja, 93,2\% ( $\mathrm{N}=55)$, afirmou que seu filho havia sido amamentado no seio. Desses, 54,5\% $(\mathrm{N}=30)$ foram aleitados naturalmente por um período maior ou igual a seis meses, e 45,5\% (N=25) parou a amamentação antes dos seis meses. Do total dos que receberam aleitamento materno, 60\% ( $\mathrm{N}=33)$ não foram alimentados exclusivamente no seio.

Quanto ao uso de mamadeira, pôde-se verificar que a maioria dos pais, ou seja, 91,5\% ( $\mathrm{N}=54)$ afirmaram que seu filho a utilizou. Desses, $88,9 \%(\mathrm{~N}=48)$ utilizava bico comum e apenas $11,1 \%(\mathrm{~N}=6)$ o bico ortodôntico.

A frequência do uso da mamadeira foi maior para mais de duas vezes por dia, $72,2 \%(\mathrm{~N}=39)$, seguida de duas vezes por dia, 16,7\% (N=9), e apenas uma vez por dia, 11,1\% (N=6).

Quanto ao uso de chupeta, 55,9\% ( $\mathrm{N}=33)$ dos pais assinalaram que seu filho a utilizou. Desses, $48,5 \%(\mathrm{~N}=16)$ utilizavam constantemente; $45,5 \%(\mathrm{~N}=15)$ apenas para dormir e $6,1 \%$ $(\mathrm{N}=2)$ fizeram ou ainda fazem uso raramente. Além disso, com relação ao tipo de bico, $72,7 \%(\mathrm{~N}=24)$ utilizava bico comum e 27,3\% (N=9) o bico ortodôntico. 
No que diz respeito à sucção digital, $74,6 \%(\mathrm{~N}=44)$ dos pais afirmaram que seu filho não fazia uso desse hábito e 25,4\% $(\mathrm{N}=15)$ afirmaram que seu filho apresentou sucção digital.

Com relação à frequência desse hábito, dos que fizeram ou ainda fazem sucção digital, $80 \%(\mathrm{~N}=12)$ dos pais assinalaram ser constantemente, $13,3 \%(\mathrm{~N}=2)$ somente para dormir e 6,7\% $(\mathrm{N}=1)$ raramente.

A Tabela 1 mostra o uso da mamadeira, chupeta e sucção digital em relação ao tempo.

Tabela 1. Duração dos hábitos orais

\begin{tabular}{lccccc}
\hline Hábito & \multicolumn{2}{c}{$\leq 3$ anos } & \multicolumn{2}{c}{$>$ anos } & Valor de $\mathrm{p}$ \\
\cline { 2 - 6 } & $\mathrm{N}$ & $\%$ & $\mathrm{~N}$ & $\%$ & \\
\hline Mamadeira & 34 & 63 & 20 & 37 & $0,007^{*}$ \\
Chupeta & 19 & 57,6 & 14 & 42,4 & 0,218 \\
Sucção digital & 0 & 0 & 15 & 100 & $<0,001^{*}$ \\
\hline
\end{tabular}

Teste de Igualdade de Duas Proporções

* Valores significativos

Legenda: \% = valor relativo; $\mathrm{N}$ = tamanho da amostra

Foi verificada a existência de diferença entre os tempos de parada para os hábitos de mamadeira e sucção digital, onde, para a mamadeira, a grande maioria estatística, ou seja, $63 \%(\mathrm{~N}=34)$ parou até os três anos. Já para a sucção digital observou-se o contrário, ou seja, $100 \%(\mathrm{~N}=15)$ fizeram ou ainda fazem uso desse hábito com idade superior a três anos.

Neste estudo verificou-se que $98,30 \%$ ( $\mathrm{N}=58$ ) das crianças, todas com mordida aberta anterior, apresentaram hábitos de sucção como mamadeira, chupeta e sucção digital.

Entre os hábitos orais, pôde-se verificar que o uso isolado da mamadeira foi o que mais ocorreu, com $22 \%$ ( $\mathrm{N}=13$ ), assim como a utilização associada da mamadeira e da chupeta, com 49,2\% ( $\mathrm{N}=29)$ (Tabela 2).

$\mathrm{Na}$ associação entre o aleitamento materno e os hábitos orais (Tabela 3), pôde-se observar que, das crianças que não foram amamentadas no seio materno, que corresponderam a $6,8 \%(\mathrm{~N}=4)$ da amostra final, $100 \%(\mathrm{~N}=4)$ utilizaram mamadeira, assim como a chupeta. Ao contrário, $100 \%(\mathrm{~N}=4)$ das crianças que não amamentaram no seio não fizeram sucção digital. Contudo, não existe relação e/ou associação entre o aleitamento materno e os hábitos orais.
Tabela 2. Uso dos hábitos orais isolados e associados entre si

\begin{tabular}{lcc}
\hline Hábitos combinados & $\mathrm{N}$ & $\%$ \\
\hline Chupeta & 1 & 1,7 \\
Sucção digital & 3 & 5,1 \\
Mamadeira & 13 & 22 \\
Mamadeira/Chupeta & 29 & 49,2 \\
Mamadeira/Sucção digital & 9 & 15,3 \\
Mamadeira/Chupeta/Sucção digital & 3 & 5,1
\end{tabular}

Teste de Igualdade de Duas Proporções

Legenda: $\%$ = valor relativo; $\mathrm{N}=$ tamanho da amostra

Ao perguntar aos pais se o filho mantinha constantemente a boca aberta durante o dia, 52,5\% (N=31) respondeu que "não" e 47,5\% (N=28) respondeu "sim". No entanto, com relação ao período noturno, a resposta mais prevalente foi "sim", com $93,2 \%(\mathrm{~N}=55)$ e $6,8 \%(\mathrm{~N}=4)$ respondeu "não".

$\mathrm{Na}$ associação do hábito de manter a boca aberta durante o dia com os hábitos orais (Tabela 4), pôde-se notar que $47,5 \%(\mathrm{~N}=28)$ das crianças permaneciam com a boca aberta durante o dia. Destes, 96,4\% ( $\mathrm{N}=27)$ também faziam uso de mamadeira, $50 \%(\mathrm{~N}=14)$, uso de chupeta e $25,5 \%(\mathrm{~N}=7)$ realizavam sucção digital. No entanto, a associação não foi significativa.

Quando observada a associação entre a permanência de boca aberta durante a noite com os hábitos orais (Tabela 5), verificou-se que $93,2 \%(\mathrm{~N}=55)$ dos pais responderam que seu filho mantinha a boca aberta durante a noite. Destes, $90,9 \%$ $(\mathrm{N}=50)$ destes também faziam uso de mamadeira, $54,5 \%$ $(\mathrm{N}=30)$ de chupeta e $25,5 \%(\mathrm{~N}=14)$ sucção digital, mas a associação não foi significativa.

Quanto aos aspectos respiratórios, houve maior porcentagem de pais que indicaram a presença de dor de garganta, com $71,2 \%(\mathrm{~N}=42)$, e presença de resfriados constantes, com $67,8 \%(\mathrm{~N}=40)$. Para os demais, foi obtido o percentual de $15,3 \%(\mathrm{~N}=9)$ para bronquite e alergia, $8,5 \%(\mathrm{~N}=5)$ para outros problemas respiratórios e 1,7\% $(\mathrm{N}=1)$ para sinusite.

Ao questionar o acompanhamento com alguns profissionais da saúde, 20,3\% ( $\mathrm{N}=12)$ indicaram ir ao otorrinolaringologista, $16,9 \%(\mathrm{~N}=10)$ ao odontopediatra, $11,9 \%(\mathrm{~N}=7)$ ao fonoaudiólogo e $6,8 \%(\mathrm{~N}=4)$ ao ortodontista.

Tabela 3. Associação entre o aleitamento materno e hábitos orais

\begin{tabular}{|c|c|c|c|c|c|c|c|c|}
\hline \multirow{3}{*}{ Hábitos } & & \multicolumn{4}{|c|}{ Aleitamento materno } & \multirow{2}{*}{\multicolumn{2}{|c|}{ Total }} & \multirow{3}{*}{ Valor de $p$} \\
\hline & & \multicolumn{2}{|c|}{ Não } & \multicolumn{2}{|c|}{$\operatorname{Sim}$} & & & \\
\hline & & $\mathrm{N}$ & $\%$ & $\mathrm{~N}$ & $\%$ & $\mathrm{~N}$ & $\%$ & \\
\hline \multirow[t]{2}{*}{ Mamadeira } & Não & 0 & 0 & 5 & 9,1 & 5 & 8,5 & 0,528 \\
\hline & $\operatorname{Sim}$ & 4 & 100 & 50 & 90,9 & 54 & 91,5 & \\
\hline \multirow[t]{2}{*}{ Chupeta } & Não & 0 & 0 & 26 & 47,3 & 26 & 44,1 & 0,066 \\
\hline & Sim & 4 & 100 & 29 & 52,7 & 33 & 55,9 & \\
\hline \multirow[t]{2}{*}{ Sucção digital } & Não & 4 & 100 & 40 & 72,7 & 44 & 74,6 & 0,226 \\
\hline & $\operatorname{Sim}$ & 0 & 0 & 15 & 27,3 & 15 & 25,4 & \\
\hline Total & & 4 & 6,8 & 55 & 93,2 & 59 & 100 & \\
\hline
\end{tabular}

Teste Qui-quadrado

Legenda: \% = valor relativo; $\mathrm{N}=$ tamanho da amostra 
Tabela 4. Associação do hábito de manter a boca aberta durante o dia com os hábitos orais

\begin{tabular}{|c|c|c|c|c|c|c|c|c|}
\hline \multirow{3}{*}{ Hábitos } & & \multicolumn{4}{|c|}{ Hábito de manter a boca aberta (dia) } & \multirow{2}{*}{\multicolumn{2}{|c|}{ Total }} & \multirow{3}{*}{ Valor de $p$} \\
\hline & & \multicolumn{2}{|c|}{ Não } & \multicolumn{2}{|c|}{ Sim } & & & \\
\hline & & $\mathrm{N}$ & $\%$ & $\mathrm{~N}$ & $\%$ & $\mathrm{~N}$ & $\%$ & \\
\hline \multirow[t]{2}{*}{ Mamadeira } & Não & 4 & 12,9 & 1 & 3,6 & 5 & 8,5 & 0,199 \\
\hline & $\operatorname{Sim}$ & 27 & 87,1 & 27 & 96,4 & 54 & 91,5 & \\
\hline \multirow[t]{2}{*}{ Chupeta } & Não & 12 & 38,7 & 14 & 50 & 26 & 44,1 & 0,383 \\
\hline & $\operatorname{Sim}$ & 19 & 61,3 & 14 & 50 & 33 & 55,9 & \\
\hline \multirow[t]{2}{*}{ Sucção digital } & Não & 23 & 74,2 & 21 & 75 & 44 & 74,6 & 0,943 \\
\hline & $\operatorname{Sim}$ & 8 & 25,8 & 7 & 25 & 15 & 25,4 & \\
\hline Total & & 31 & 52,5 & 28 & 47,5 & 59 & 100 & \\
\hline
\end{tabular}

Teste Qui-quadrado

Legenda: $\%$ = valor relativo; $\mathrm{N}=$ tamanho da amostra

Tabela 5. Associação do hábito de manter a boca aberta durante a noite com os hábitos orais

\begin{tabular}{|c|c|c|c|c|c|c|c|c|}
\hline \multirow{3}{*}{ Hábitos } & & \multicolumn{4}{|c|}{ Hábito de manter a boca aberta (noite) } & \multirow{2}{*}{\multicolumn{2}{|c|}{ Total }} & \multirow{3}{*}{ Valor de $\mathrm{p}$} \\
\hline & & \multicolumn{2}{|c|}{ Não } & \multicolumn{2}{|c|}{ Sim } & & & \\
\hline & & $\mathrm{N}$ & $\%$ & $\mathrm{~N}$ & $\%$ & $\mathrm{~N}$ & $\%$ & \\
\hline \multirow[t]{2}{*}{ Mamadeira } & Não & 0 & 0 & 5 & 9,1 & 5 & 8,5 & 0,528 \\
\hline & Sim & 4 & 100 & 50 & 90,9 & 54 & 91,5 & \\
\hline \multirow[t]{2}{*}{ Chupeta } & Não & 1 & 25 & 25 & 45,5 & 26 & 44,1 & 0,426 \\
\hline & Sim & 3 & 75 & 30 & 54,5 & 33 & 55,9 & \\
\hline \multirow[t]{2}{*}{ Sucção digital } & Não & 3 & 75 & 41 & 74,5 & 44 & 74,6 & 0,984 \\
\hline & Sim & 1 & 25 & 14 & 25,5 & 15 & 25,4 & \\
\hline Total & & 4 & 6,8 & 55 & 93,2 & 59 & 100 & \\
\hline
\end{tabular}

Teste Qui-quadrado

Legenda: $\%$ = valor relativo; $\mathrm{N}=$ tamanho da amostra

\section{DISCUSSÃO}

A literatura fonoaudiológica, assim como a odontológica, traz diversos estudos que buscam comprovar que a manutenção de hábitos orais pode causar alterações na oclusão dentária, bem como no crescimento craniofacial. Com esta relação, a mordida aberta anterior é a má oclusão mais prevalente encontrada na dentição decídua ${ }^{(2,5,14-17)}$.

Acreditando na importância da prevenção e de uma intervenção precoce junto a esses casos, este estudo possui grande relevância pela escassez de pesquisas sobre esse tema na cidade de Rio Branco (AC).

Neste estudo, observou-se mordida aberta anterior em $21,45 \%$ ( $N=59)$ das 275 crianças avaliadas, percentual similar aos de Aracajú (SE), com 24,1\% do total de 216 crianças $^{(3)}$ e Natal (RN), sendo encontrada a mordida aberta anterior em 20,6\% do total de 366 crianças $^{(5)}$; inferior ao encontrado nos estudos de Florianópolis (SC), com 27,5\% do total de 233 crianças $^{(2)}$; de Fortaleza (CE), com 35\% do total de 130 crianças $^{(18)}$ e de Belo Horizonte (MG), com $27 \%$ do total de 168 crianças; e superior ao percentual do estudo em Governador Valadares (MG), com 17,14\% do total de 35 crianças $^{(15)}$ e de Jundiaí (SP), com 18,9\% do total de 164 pré-escolares $\operatorname{avaliados}^{(9)}$.

Essa diferença, em relação à prevalência, pode ser explicada pelas características de cada população estudada como: fatores socioeconômico-culturais das populações, prevalência de hábitos de sucção não-nutritiva, assim como pelos diferentes tamanhos das amostras, concordando com outros estudos ${ }^{(2,5)}$.

Embora tenha sido verificado um maior percentual de meninas com mordida aberta anterior $(57,6 \%)$, não se pode dizer, de acordo com dados estatísticos, que exista diferença estatística para o percentual de meninos $(42,4 \%)$. Este achado já era esperado em conformidade com outros estudos revisados, alguns com prevalência maior de má oclusão no gênero feminino $^{(2,5,19)}$, outro no gênero masculino ${ }^{(3)}$, mas que também não demonstraram diferenças significativas na frequência dos problemas oclusais entre os gêneros masculino e feminino.

Vários estudos também utilizaram questionário com pais para levantamento de características das crianças ${ }^{(5,11,14)}$.

Verifica-se um elevado percentual de crianças, ou seja, $93,2 \%$, que recebeu aleitamento natural ao nascimento, assim como indicado pela maioria dos estudos revisados ${ }^{(5,14,16,20-22)}$. No entanto, dessas, 54,5\% foram amamentadas por um período maior ou igual do que seis meses. $\mathrm{O}$ aleitamento artificial exclusivo desde o nascimento ocorreu apenas para um pequeno número (6,8\%). Estes resultados equiparam-se com os do estudo realizado em Florianópolis $(\mathrm{SC})^{(21)}$.

Apesar de não existir, neste estudo, diferença entre o percentual de sujeitos que pararam de ser amamentados no seio em período menor que seis meses $(45,5 \%)$ e maior que seis meses $(54,5 \%)$, os resultados não coincidem com os achados 
na literatura que afirmam que, no Brasil, praticamente todas as crianças são inicialmente amamentadas no seio materno, apesar de esta prática perdurar geralmente pouco tempo ${ }^{(21)}$.

A maioria das crianças, ou seja, $60,0 \%(\mathrm{~N}=35)$ não foi amamentada exclusivamente no seio, o que provavelmente pode ter contribuído para a prevalência de seus hábitos orais, concordando que há associação entre o aleitamento natural e a não instalação de hábitos orais ${ }^{(23)}$.

O tempo de uso dos hábitos orais foi considerado como menor ou igual a três anos e maior que três anos. Esse aspecto foi baseado em dados da literatura que referem haver chance de ocorrer auto-correção de alguma desarmonia oclusal, causada pelo hábito, se mantido por período menor ou igual a três anos, e que a partir dessa idade, causará alterações orofaciais comprometedoras do crescimento facial harmônico ${ }^{(1,4)}$.

Em relação ao hábito da mamadeira, pôde-se verificar que a maioria dos pais $(91,5 \%)$ afirmou que seu filho fez uso de mamadeira. Este dado, assim como os de outras pesquisas, comprova que tal hábito é bastante frequente em crianças, mesmo nos grupos com idades mais avançadas ${ }^{(11,20)}$.

No entanto, com relação ao tempo de uso da mamadeira, a grande maioria (63\%) fez uso apenas até os três anos, tendo sido encontrado um percentual menor de crianças (37\%) que fizeram ou ainda fazem uso de mamadeira por um período maior que três anos. Esse dado foi inferior ao do estudo de Manaus (AM), no qual, na escola particular e na pública, predominou tal hábito em idade superior aos três anos de idade, $52,9 \%$ e $55,9 \%$, respectivamente ${ }^{(20)}$.

Com relação ao tipo de bico da mamadeira, $88,9 \%$ das crianças fizeram uso do bico comum e $11,1 \%$, do bico ortodôntico. Tal resultado é próximo ao do estudo realizado em Porto Alegre (RS), com 37 crianças, no qual $71 \%$ usaram bico da mamadeira não ortodôntico, levando os autores à conclusão de que o uso de mamadeira com bico que não seja ortodôntico causa um grande desequilíbrio funcional e muscular ${ }^{(20)}$.

Ainda com relação à mamadeira, ao questionar sobre a frequência de seu uso, percebemos que a grande maioria dos pais, ou seja, 72,2\%, afirmou que seu filho a utiliza/utilizou por mais de duas vezes por dia, fator que é considerado na associação de hábitos orais com alterações dentárias e oclusais ${ }^{(8)}$.

Dos pais que informaram que os filhos utilizaram chupeta (55,9\% da amostra), 48,5\% indicaram que o uso era constante, e $45,5 \%$ indicaram que a chupeta era utilizada apenas para dormir, podendo estar associada à presença de má oclusão ${ }^{(6)}$.

Com relação ao tempo de uso, 57,6\% das crianças usaram chupeta por um período igual ou inferior aos três anos, enquanto $42,4 \%$ a utilizaram mais que três anos, o que não pode ser considerado uma diferença significativa entre os percentuais de resposta. Dessa forma, observou-se que houve diminuição da utilização da chupeta após os três anos, dado semelhante aos obtidos em outras pesquisas, nas quais foram observadas uma discreta diminuição da prevalência de hábitos de sucção não-nutritiva com o avançar da idade, podendo estar associado à maturidade adquirida pela criança ${ }^{(2,11)}$. No entanto, entre os hábitos orais de utilização de chupeta, mamadeira e sucção digital realizados após os três anos de idade, o percentual de uso da chupeta foi o maior encontrado em nosso estudo.
Com relação ao tipo de chupeta, do total de crianças que a utilizou, $72,7 \%$ fez uso do bico comum e $27,3 \%$ do ortodôntico. Em estudo realizado em Belo Horizonte (MG), não foi encontrada associação significativa entre o tipo de chupeta utilizada e a presença de mordida aberta anterior, uma vez que, das 117 crianças avaliadas entre três e seis anos, 83 eram suctoras de chupeta ortodôntica e destas, 26,5\% apresentavam mordida aberta anterior, enquanto a maioria $(73,5 \%)$ não tinha a presença desta má oclusão ${ }^{(17)}$.

No que diz respeito à sucção digital, a maioria dos pais (74,6\%), afirmou que seu filho não apresentou esse hábito. $\mathrm{O}$ percentual de crianças que faziam sucção digital foi de $25,4 \%$. No entanto, destes, $100 \%$ fizeram ou ainda fazem uso desse hábito por um período superior aos três anos de idade.

Com relação à frequência, dos que fizeram ou ainda fazem uso desse hábito, a grande maioria dos pais, ou seja, $80 \%$ assinalaram ser constantemente.

A sucção digital, embora tenha sido a menos prevalente encontrada neste estudo, assim como na maioria dos estudos revisados ${ }^{(6,9,11,17,24,25)}$, é apontada como mais prejudicial do que a sucção de chupeta, pois o dedo exerce maior pressão sobre a cavidade oral e é de fácil acesso ${ }^{(18)}$. Provavelmente seja por essa facilidade de acesso que, todas as crianças do nosso estudo (100\%) que fizeram uso desse hábito, ultrapassaram o período de três anos.

A combinação de hábitos mais prevalente foi de mamadeira/chupeta, com 49,2\%, conforme outros estudos ${ }^{(9,12,20,26)}$.

Ao perguntar se seu filho mantinha constantemente a boca aberta durante o dia, a maioria dos pais respondeu que "não", com 52,5\% (N=31). No entanto, com relação à boca aberta durante a noite, a resposta mais prevalente dos pais foi "sim", com 93,2\% ( $\mathrm{N}=55)$, o que apresenta diferença significativa entre o percentual das respostas.

De acordo com os registros dos pais, as crianças que ficavam constantemente com a boca aberta durante o dia, 96,4\% $(\mathrm{N}=27)$ também fazia uso de mamadeira, 50\% ( $\mathrm{N}=14)$ uso de chupeta e $25 \%(\mathrm{~N}=7)$ sucção digital.

Com relação a manter constantemente a boca aberta durante a noite, $90,9 \%(\mathrm{~N}=50)$ das crianças também faziam uso de mamadeira, 54,5\% ( $\mathrm{N}=30)$ de chupeta e $25,5 \%(\mathrm{~N}=14)$ sucção digital.

A permanência da boca aberta não significa presença de respiração oral, pois o bloqueio da passagem de ar pela cavidade oral pode ser realizado, além dos lábios, pela língua no palato. Neste estudo não foi realizada nenhuma avaliação que confirmassem a presença de respiração oral. Mas há vários estudos que confirmam a relação da respiração oral com a mordida aberta anterior ${ }^{(10,25,27)}$.

Um estudo retrospectivo pela análise de 41 prontuários de crianças respiradoras orais entre sete e 12 anos de idade verificou a relação entre má oclusão e hábitos orais em um grupo de respiradores orais. Os resultados mostraram que todas as crianças apresentavam algum tipo de má oclusão, predominando a classe II de Angle e a sobressaliência acentuada, e o hábito mais acentuado foi o de colocação de objetos na boca ${ }^{(28)}$.

Sobre problemas respiratórios que a criança apresenta, os resultados demonstraram que houve maior porcentagem de pais que indicaram a presença de dor de garganta $71,2 \%$ 
( $\mathrm{N}=42)$, mas que não é tão diferente do percentual da presença de resfriados constantes de 67,8\% (N=40).

A presença de qualquer obstáculo no sistema respiratório, especialmente na região nasal e/ou faríngea, vai ocasionar obstrução nasal, obrigando o paciente a respirar pela boca, como demonstra o estudo realizado em Marília (SP) com 104 crianças entre três e dez anos de idade onde se diagnosticou rinite alérgica em 32,69\% ( $\mathrm{N}=34)$, hipertrofia de adenóide em 11,54\% ( $\mathrm{N}=12)$, hipertrofia de amígdala em 3,85\% (N=4) e hábito com 7,69\% $(\mathrm{N}=8)^{(29)}$.

Os respiradores orais estão mais predispostos a repetidos resfriados, tosse espasmódica e rouquidão ${ }^{(27)}$. Com relação ao tipo de acompanhamento já realizado pelas crianças, o que mais nos chamou atenção foi a baixa procura pelo ortodontista $6,8 \%(\mathrm{~N}=4)$ e o fonoaudiólogo $11,9 \%(\mathrm{~N}=7)$, mesmo se tratando de crianças que apresentam mordida aberta anterior e alta prevalência de hábitos orais, e tendo esses profissionais grande papel na intervenção de tais problemas.

Do ponto de vista fonoaudiológico e ortodôntico, o tratamento para este tipo de anomalia deve ser precoce, para prevenir desarmonias ósseas severas e evitar intervenções cirúrgicas de maior complexidade. O tratamento fonoaudiológico precoce, muitas vezes, soluciona essas anomalias sem necessidade de tratamento ortodôntico ${ }^{(24)}$. O tratamento precoce da mordida aberta anterior mostrou apresentar grande efetividade clínica, devido ao curto período de tempo, à estabilidade de uma oclusão adequada e à utilização de uma mecanoterapia simples, como a grade lingual, possibilitando o desenvolvimento e crescimento harmonioso da face ${ }^{(30)}$.
Portanto, verificando as inúmeras alterações que os hábitos orais podem provocar no sistema estomatognático, acreditamos que a retirada de tais hábitos e o trabalho fonoaudiológico precoce, além de outros fatores, facilitam a harmonia do crescimento dentofacial. Uma vez que é dada condição para uma adequada postura dos lábios e língua, evita-se futuras alterações oclusais. Dessa forma, o fonoaudiólogo tem fundamental importância na prevenção, detecção e retirada dos hábitos, diminuindo a ocorrência das alterações.

Queremos ressaltar que os dados obtidos nessa pesquisa não podem ser tomados como conclusivos, por terem sido considerados apenas dados obtidos através de questionário. Fica a sugestão para um novo estudo que envolva um exame clínico das estruturas da cavidade oral como palato duro e bochechas, a postura habitual dos lábios e da língua, bem como avaliação quanto ao modo respiratório.

\section{CONCLUSÃO}

Verificou-se presença de mordida aberta anterior na menor parte dos pré-escolares, na idade entre quatro e seis anos e na dentadura decídua completa, na cidade de Rio Branco (Acre). Dentre os hábitos de sucção, a associação mais prevalente foi de mamadeira e chupeta. A maioria das crianças com mordida aberta anterior apresentou hábitos de sucção como mamadeira, chupeta e dedo. Foi encontrada maior ocorrência de crianças que permaneciam com a boca aberta durante a noite e que também faziam uso de mamadeira.

\begin{abstract}
Purpose: To verify the number of preschool children with anterior open bite and the association with oral habits. Methods: The universe of the study was formed by 275 preschool children, both male and female, with ages between four and six years, and complete deciduous dentition. This study was developed in two stages: a screening to select the children who presented anterior open bite, and the application of a questionnaire with the parents/caregivers of the 59 children with anterior open bite regarding maternal breastfeeding and oral habits. Data were statistically using the Two-proportion Equality test and the Chi-square test. Results: The proportion of children with anterior open bite was of $21.45 \%(\mathrm{~N}=59)$, with no variation according to gender. It was verified that 93.20\% ( $\mathrm{N}=55)$ of the subjects were breastfed, and 54.5\% ( $\mathrm{N}=30)$ of them was breastfed for six months or more. Most children with open bite, $98.30 \%(\mathrm{~N}=58)$, presented suction habits (baby bottle, pacifier, fingers). A higher occurrence was found among the children that remained with their mouths opened during the night and also used baby bottles (90.9\%). Amongst the oral habits, the most prevalent association was between the bottle and the pacifier, with $49.2 \%$. Conclusion: The results indicated the presence of anterior open bite, the associated use of bottle and pacifier. Moreover, the data indicated a relationship between anterior open bite and oral habits such as bottles and pacifiers, and between children who remained with their mouths opened at night and also used baby bottles.
\end{abstract}

Keywords: Preschool; Open bite; Nursunig bottles; Fingersucking; Mouth breathing; Breast feeding

\title{
REFERÊNCIAS
}

1. Petrelli E, coordenador. Ortodontia para fonoaudiologia. São Paulo: Lovise; c1992.

2. Forte FDS, Bosco VL. Prevalência de mordida aberta anterior e sua relação com hábitos de sucção não nutritiva. Pesqui Bras Odontopediatria Clin Integr. 2001;1(1):3-8.
3. Santana VC, Santos RM, Silva LAS, Novais SMA. Prevalência de mordida aberta anterior e hábitos bucais indesejáveis em crianças de 3 a 6 anos incompletos na cidade de Aracaju. J Bras Odontopediatr Odontol Bebe. 2001;4(18):153-60.

4. Moyers RE. Ortodontia. 4a. ed. Rio de Janeiro: Guanabara Koogan; 1991. 
5. Sousa RLS, Lima RB, Florêncio Filho C, Lima KC, Diógenes AMN. Prevalência e fatores de risco da mordida aberta anterior na dentadura decídua completa em pré-escolares na cidade de Natal/RN. Rev Dent Press Ortodon Ortopedi Facial. 2007;12(2):129-38.

6. Tomita NE, Bijella VT, Franco LJ. Relação entre hábitos bucais e má oclusão em pré-escolares. Rev Saúde Pública $=\mathrm{J}$ Public Health 2000;34(3):299-303.

7. Emmerich A, Fonseca L, Elias AM, Medeiros UV. Relação entre hábitos bucais, alterações oronasofaringianas e mal-oclusões em pré-escolares de Vitória, Espírito Santo, Brasil. Cad Saúde Pública = Rep Public Health. 2004;20(3):689-97.

8. Albuquerque HR, Barros AMM, Braga JPV, Carvalho MF, Maia MCG. Hábito bucal deletério e má-oclusão em pacientes da clínica infantil do curso de odontologia da Universidade de Fortaleza. Rev Bras Prom Saúde. 2006;20(1):40-5.

9. Soligo MO. Hábitos de sucção e má-oclusão: repensando esta relação. Rev Dent Press Ortodon Ortop Facial. 1999;4(6):58-64.

10. Andrade FV, Andrade DV, Araújo AS, Ribeiro ACC, Deccax LDG, Nemr K. Alterações estruturais de órgãos fonoarticulatórios e más oclusões dentárias em respiradores orais de 6 a 10 anos. Rev CEFAC. 2005;7(3):318-25.

11. Verrastro AP, ashima AY, Ideriha P, Stefani FM, Rodrigues CRMD, Wanderley MT. Características oclusais e miofuncionais orais das crianças atendidas na Clínica de Odontopediatria da Faculdade de Odontologia da USP. Rev Inst Ciênc Saúde. 2009;27(4):394-9.

12. Galvão ACUR, Menezes SFL, Nemr K. Correlação de hábitos orais deletérios entre crianças de 4 a 6 anos de escola pública e escola particular da cidade de Manaus - AM. Rev CEFAC. 2006;8(3):328-36.

13. Fayyat ELRC. A influência de hábitos orais e respiração bucal no aparecimento de mordida aberta anterior em crianças com dentição decídua. Fono Atual. 2000;3(12):36-40.

14. Fonseca JS, Martins GA. Curso de estatística. 6a. ed. São Paulo: Atlas; 1996.

15. Sousa FRN, Taveira GS, Almeida RVD, Padilha WWN. O aleitamento materno e sua relação com hábitos deletérios e maloclusão dentária. Pesqui Bras Odontopediatria Clin Integr. 2004;4(3):211-6.

16. Souza NB, Vasconcelos TC. A influência de hábitos orais como fator etiológico de mordida aberta anterior. Rev CEFAC. 2003;5(3):235-40.

17. Bezerra PKM, Cavalcanti AL, Bezerra PM, Moura C. Maloclusões, tipos de aleitamento e hábitos bucais deletérios em pré-escolares - um estudo de associação. Pesqui Bras Odontopediatria Clin Integr. 2005;5(3):26774.
18. Chevitarese AB, Della Valle D, Moreira TC. Prevalence of malocclusion in 4-6 year old Brazilian children. J Clin Pediatr Dent. 2002;27(1):81-5.

19. Ignacchiti PR, Gesualdi KC, Cursage FPC, Almada RO. Hábito de sucção de chupeta e mordida aberta anterior na criança com dentição decídua. Rev CEFAC. 2003;5(3):241-5.

20. Soncini F, Dornelles S. Ocorrência de hábitos orais nocivos em crianças com 4 anos de idade, de creches públicas no município de Porto Alegre (RS), Brasil. Pró-Fono. 2000;12(2):103-8.

21. Czernay APC, Bosco VL. A Introdução precoce e o uso prolongado da mamadeira: ainda uma realidade. JBP J Bras Odontopediatr Odontol Bebê. 2003;6(30):138-44.

22. Leite-Cavalcanti A, Medeiros-Bezerra PK, Moura C. Aleitamento natural, aleitamento artificial, hábitos de sucção e maloclusões em préescolares brasileiros. Rev Saúde Pub. 2007;9(2):194-204.

23. Serra Negra JMC, Pordeus IA, Rocha Júnior JF. Estudo da associação entre aleitamento, hábitos bucais e maloclusões. Rev Odontol Univ São Paulo. 1997;11(2):79-86.

24. Maciel CTV, Leite ICG. Aspectos etiológicos da mordida aberta anterior e suas implicações nas funções orofaciais. Pró-Fono. 2005;17(3):293302.

25. Ribeiro F, Mesquita MCM, Assencio-Ferreira VJ. Respiração oral: alterações oclusais e hábitos orais. Rev CEFAC. 2002;4(3):187-90.

26. Czlusniak GR, Carvalho FC, Oliveira JP. Alterações de motricidade orofacial e presença de hábitos nocivos orais em crianças de 5 a 7 anos de idade: implicações para intervenções fonoaudiológicas em âmbito escolar. Publ UEPG Ci Biol Saúde. 2008;14(1):29-39.

27. Menezes VA, Leal RB, Pessoa RS, Pontes RMES. Prevalência e fatores associados à respiração oral em escolares participantes do projeto Santo Amaro-Recife, 2005. Rev Bras Otorrinolaringol. 2006;72(3):394-9.

28. Almeida FL, Silva AMT, Serpa EO. Relação entre má oclusão e hábitos orais em respiradores orais. Rev CEFAC. 2009;11(1):86-93.

29. Motonaga SM, Berte LC, Anselmo-Lima WT. Respiração bucal: causas e alterações no sistema estomatognático. RBORL. 2000;66(4):373-9.

30. Tagawa DT, Aidar LAA, Tagawa PT. Intervenção precoce na mordida aberta anterior. Rev Assoc Paul Cir Dent. 2009;63(1):44-8. 